\title{
How and why to use low temperature treatment in the rice breeding?
}

\author{
Árpád SZÉKELY ${ }^{1}$ - Tímea SZALÓKI ${ }^{1}$ - Beáta VITÁNYI ${ }^{1}$ - Mihály JANCSÓ ${ }^{1}$ - \\ János PAUK ${ }^{2}$ - Csaba LANTOS ${ }^{2}$ \\ 1: National Agricultural Research and Innovation Centre, Research Institute of Irrigation of Water Management; \\ Anna liget u.35, H-5540, Szarvas, Hungary E-mail: szekely.arpad@ovki.naik.hu \\ 2: Cereal Research Non-profit Ltd., Alsó kikötő sor 9, H-6726, Szeged, Hungary; E-mail: csaba.lantos@ \\ gabonakutato.hu
}

Keywords: rice, cold tolerance, doubled haploid

\section{Introduction}

One of the most important traits is low temperature germinability (LTG) in seedling establishment in direct-sowing of rice. An important breeding aim is to develop varieties, which are tolerant to low temperatures at critical growth stages (Nakagahra et al., 1997). In generally, the breeding programmes include screening for chilling sensitivity of different rice genotypes under field conditions (Andaya and Mackill 2003). However, selection of cold tolerant varieties in field condition is difficult, because of the unpredicted intensity and duration of the cold periods. Nanculao et al. (2013) and Cruz and Milach (2004) mentioned that the coleoptiles length is suitable to find differences among rice genotypes under $13^{\circ} \mathrm{C}$. Hungarian researchers found a minimum temperature at $12^{\circ} \mathrm{C}$ for the germination (Gombos and Simon-Kiss 2008). Double haploid lines (DH) serve an opportunity to shorten the breeding time. And in our breeding programme, hundreds of unique DH plants have been produced annually. But evaluation of these materials is hard. Our goal was to develop a fast, repeatable and early screening method to evaluate cold tolerance of new rice lines.

\section{Materials and methods}

The germination parameters (germination percentage - GP, median germination time E50, germination speed - R50 and the lag period) were described in our earlier paper (Székely 2016). These parameters were calculated for 14 rice cultivars and DH lines at $12^{\circ} \mathrm{C}$. The $12 \mathrm{DH}$ lines originated from one crossing of Nembo and Köröstáj 333. The germination experiment at $12^{\circ} \mathrm{C}$ lasts for 25 days.

\section{Results and discussion}

In the first experiment the germination was failure, there was no noticeable germination process neither breeding lines nor released varieties. Under chilling stress, all varieties showed lower GP, longer lag period, lower R50 and lower E50 than in control condition. Because of the very slow and fragmented germination process at $12^{\circ} \mathrm{C}$, we could not calculate adequately the E50 and R50 values in all lines. Accordingly, we use GP and lag period to find differences among the varieties. Based on Szalóki's data (Szalóki et al. 2018) the increasing lag period resulted in decreasing GP. The correlation was linear. We found the same correlation in case of released varieties. However, DH lines did not show this correlation. The shortest lag periods were found in 42.IV (11.17 \pm 0.76$)$ and 42.I. $(11.50 \pm 0.00)$ among the DH lines although these lines had longer lag period as compared with parents'values (Table 1). In case of GP, there were two genotypes (5.I. and 42.IV.), 
which reached the parental values. Based on the examined parameters there were two lines (22.II. and 9.I) which had the least germination process.

Table 1: The germination parameters of the $12 \mathrm{DH}$ lines and two released variety

\begin{tabular}{|c|c|c|c|c|c|c|c|}
\hline Genotype & LAG & Genotype & LAG & Genotype & GP & Genotype & GP \\
\hline Nembo & $9.5 \pm 1.73$ & 5.I. & $12.83 \pm 0.58$ & Köröstáj 333 & $83.33 \pm 5.77$ & 9.II. & $50.83 \pm 8.04$ \\
\hline $\begin{array}{c}\text { Köröstáj } \\
333\end{array}$ & $10.67 \pm 1.04$ & $9 . I I I$. & $13.67 \pm 1.04$ & $5 . I$. & $82.50 \pm 5.00$ & $11 . I$. & $43.33 \pm 2.89$ \\
\hline 42.IV & $11.17 \pm 0.76$ & 10.I. & $13.67 \pm 0.29$ & 42.IV. & $80.00 \pm 4.33$ & 5.II & $42.50 \pm 10.00$ \\
\hline 42.I. & $11.50 \pm 0.00$ & 11.I & $13.67 \pm 0.76$ & Nembo & $73.33 \pm 3.82$ & 9.III. & $39.17 \pm 9.46$ \\
\hline 5.II. & $11.75 \pm 0.35$ & 9.II. & $13.83 \pm 0.29$ & 22.III. & $72.50 \pm 8.66$ & 10.I. & $36.67 \pm 3.82$ \\
\hline 42.II. & $12.50 \pm 0.87$ & 9.I. & $14.50 \pm 0.87$ & 42.II. & $68.33 \pm 1.44$ & 22.II. & $19.17 \pm 10.41$ \\
\hline 22.III. & $12.67 \pm 1.53$ & 22.II. & $15.00 \pm 1.32$ & 42.I. & $62.50 \pm 6.61$ & 9.I. & $7.50 \pm 4.33$ \\
\hline
\end{tabular}

\section{Conclusions}

According to results, the screening methods at $12^{\circ} \mathrm{C}$ is suitable for finding differences among the varieties. This method is a simple way to determine GP and lag period time. Based on our data $\left(20^{\text {th }}\right.$ day of the experiment), we can evaluate the degree of cold tolerance of different basic breeding materials. 5.I. and 42.IV are suitable for further testing and 22.II and 9.I. lines were sensitive the cold temperature.

\section{Acknowledgement}

The Hungarian Ministry of Agriculture supported the project under the "Improvement of the abiotic stress tolerance of Hungarian rice varieties” program (FM OD002). Árpád Székely is a scholarship holder of the NAIK Researchers Recruitment Programme.

\section{References}

Andaya V.C. and Mackill D.J. (2003): Mapping of QTLs associated with cold tolerance during the vegetative stage in rice. Journal of Experimental Botany, Volume 54, Issue 392, 1 November 2003, Pages 2579-2585 DOI: https://doi.org/10.1093/jxb/erg243

Gombos, B. and Simon-Kiss, I. (2008): Study and Modelling the Emergence of Five Hungarian Rice Cultivars. Cereal Research Communications. 36(3): 501-510. DOI: https://doi.org/10.1556/ CRC.36.2008.3.14

Nakagahra M, Okuno K, Vaughan D. (1997): Rice genetic resources: history, conservation, investigative characterization and use in Japan. Plant Molecular Biology 35, 69-77. DOI: https://doi.org/10.1007/978-94011-5794-0_7

Ñanculao G.D., Cárcamo M.P., Santos O.A., Velásquez V.B. (2013): Cold tolerance evaluation in Chilean rice genotypes at the germination stage. Chilean Journal of Agricultural Research 73(1):3-8. DOI: http://dx.doi. org/10.4067/S0718-58392013000100001

Szalóki T., Jancsó M., Székely Á., Vitányi B. (2018): Cold tolerance evaluation of rice (Oryza sativa L.) genotypes at the germination - and the seedling stage. 17th Alps-Adria Scientific Workshop, 56-57

Székely Á., Szalóki T., Kolozsvári I., Jancsó M. (2016): The effect of salt stress is the germination dynamics of Hungarian rice varieties. First conference of NAIK Researchers Recruitment Programme, ISBN 978-96389399-9-9, 86-91 